transmutation of elements are most commonly treated from this point of view. The problem of steric hindrance is perhaps the best example of the old outlook coming into contact with the new.

It is well known that chemists tend to adopt materialistic forms of physical entities ("when chemists talk about electrons they use a different language from physicists"); and if this is true to-day, it was so much the more difficult to escape from materialism in the nineteenth century. "For no man can live in the external truth among acids and salts", wrote Stevenson, "but in the warm phantasmagoric chamber of the brain with the painted windows and the storied wall". Stevenson could not have anticipated the phenomenalism of Mach and Karl Pearson which averted this antithesis. This was the view that the doctrine of determinist mechanism only applies to the abstract entities provided by logical analysis. Phenomenalism has never been adopted universally by scientific men, and in the nineteenth century the rift between science and philosophy encouraged the retention of a naïve realism.

Now that men of science show a renewed interest in certain philosophical problems, new opportunities have arisen for investigating the consequences of adopting the phenomenalist or realist position. The limitations of a method of abstraction would appear to incline one to phenomenalism. The only point on which one finds substantial agreement among scientific writers is that science can give us only a network of relations, and the search for the ultimate nature of substance is likely always to be fruitless. We discover relations, but the relata are defined by the relations and nothing else. In spite of this, arguments are adduced by some writers to support a scientific form of Berkeleyan idealism. The cycles of determinism which chain the mind are then broken by invoking a form of Heisenberg's uncertainty principle which has not yet gained universal approval. Human aim and value appear to be permitted simply because, as J. W. N. Sullivan explained, the cycles of determinism at present exist only in what is called 'field' physics. In the remainder of phenomena one supposes the quantum jumps are indeterminate in the sense that they cannot be fully predicted. As is well known, this is not to say they are outside any causal nexus, for we know the set limits of the effects.

The result is bleak and cheerless enough as the basis of a 'humanistic' outlook. Ethical and æsthetical considerations may still be valid, but they seem to be left over with a rather apologetic air. The whole position is Hobbesian : science, instead of being an instrument for reducing our apprehension of the world to forms providing increased control, is regarded as disclosing the nature of an objective and pre-existent reality "in its linkage to consciousness". Because there are difficulties in the old 'spectator' theory of observation, the mind is enmeshed in the determinist (or indeterminist?) scheme. If one favours ultimate determinism it is easy for the ordinary man to relapse into pure Hobbesian materialism; if one seriously tries to adopt some kind of objectivized chance, the character of Nature appears lunatic and its 'order' is only another of those illusory ideas which need exposing. On either basis it is difficult to see how science can intellectually be other than an obstacle to its own application to ethical ends. Both in education and in adult thought this is. surely the greatest problem of modern times.

1 "Wuvres Complètes de Christian Huygens", 4, 381.

ibid. 18, 554

\section{GEOPHYSICAL METHODS IN GEOLOGY}

A JOINT meeting of the London and Home A Counties Branch of the Institute of Physics and the Geological Society of London, held on April 22 , provided a useful review of the principal geophysical means now available to supplement the routine methods of geological survey. Prof. O. T. Jones opened the meeting with a brief account of the four main types of geophysical survey, which measure respectively the ground resistivity, the rate of transmission of an artificial seismic vibration and the gravitational and magnetic fields at the surface. $\mathrm{H}_{\theta}$ stressed the importance of close co-ordination between the two sides of the subject : geology might indicate the probable materials and structures, but confirmation of their actual existence and a closer estimate of their position could in many cases be best obtained by geophysical means.

It was clear that no general preference can be given to any one method. Each has its own range of suitability and its limitations, some of which were outlined in Dr. J. M. Bruckshaw's contribution. His warnings might perhaps be specially recommended to the notice of non-physicists, for complaints as to the 'failure' of geophysics have not uncommonly arisen from the quite impossible expectations put forward by uninformed critics. There are at least as many inaccessible problems in geophysics as in geological surveying; fortunately, they are not the same problems in each case.

The principal limitations arise from the necessity for adequate physical differences between the rock masses, and from instrumental difficulties. Dr. Bruckshaw pointed out that gravitational and magnetic surveys are largely differential, depending upon local irregularities in the field, produced by discontinuities in the geological structure. Thus they are particularly adapted for detecting faults, boundaries, etc., while the presence of a uniform flatlying bed would only produce zero (or constant) anomaly. But in practice some of the other methods have been used differentially to locate discontinuities even if the exact interpretation of the records is obscure. Another, and very interesting, point was the contrast between the Eötvös torsion balance and the gravimeter : for the former the values observed depend upon the inverse cube of the depth; for the latter, upon the inverse square. If the size of the structure increases proportionately with the depth, the effect to be observed with the torsion balance remains the same whatever the depth, while with the gravimeter the effect increases with the dimensions. Thus the torsion balance is in this respect better suited for shallow structures.

First-hand accounts of geophysical work in the field were given by Dr. D. T. Germain-Jones, who dealt with seismic exploration in Iran, and Dr. A. F. Hallimond, who described the magnetic work of the Geological Survey of Great Britain.

In using the seismic refraction method in Iran, the recording instruments were placed along an arc at about ten miles from the explosion point. The object of the survey was to locate an anticline believed on geological grounds to exist in the oil-bearing Asmari Limestone, which is concealed beneath the Lower Fars Series. This first conclusion was not confirmed, but further seismic observations to the south-west led to the discovery of an anticline in the limestone, concealed beneath a syncline in the surface rocks. 
This was confirmed by drilling, at a depth in agreement with the geophysical estimate, but only half that expected from neighbouring geological data. The peculiar structure is believed to be due to plastic deformation of the Lower Fars beds, which have been squeezed out above the Asmari anticline and thickened on either side.

The Geological Survey of Great Britain has employed magnetic methods at intervals since 1928. The range is restricted by the non-magnetic nature of most sedimentary rocks, but on the other hand the same fact allows a particularly satisfactory investigation of any underlying magnetic formations. A striking example of this was provided by the Survey mapping of the Melton Mowbray magnetic anomaly. The resulting contoured vertical force map bore practically no relation to the surface geology (Lias and Trias) but showed a remarkable magnetic 'high' area, with subsidiary ridges, such as might be due to igneous masses in the floor of older rocks. As a wellknown French writer has observed : "la géophysique voit flou"; from east to west the outlines in the magnetic map become sharper until a system of ridges with east-north-east trend lonks up with the anomaly due to the exposed intrusive igneous mass at Mount Sorrel. The estimated depth of the floor is from $1,500 \mathrm{ft}$. to $500 \mathrm{ft}$. across the Melton anomaly.

Oil geology has afforded perhaps the most spectacular examples of success in geophysical exploration. Indeed, the value of the new oilfields discovered has tended to obscure the large number of explorations carried out on equally adequate grounds but which happened to yield negative results. They are sometimes described as failures, but they are in reality an essential part of the research. Obviously, researches cannot be limited entirely to 'successful' results, yet in the larger commercial departments programmes are designed in the expectation of only a few per cent of even moderately 'successful' results.

A clear account of some of the outstanding geophysical achievements in oil geology was contributed by Prof. V. C. Illing. Fere the geological structures are chiefly anticlines or domes, and the principal methods employed are (1) seismic reflexion, for gently sloping structures, (2) torsion balance and seismic refraction, for steeper-sided salt-dome structutes, (3) gravity, refraction and reflexion in faulted and folded areas. Prof. Illing again stressed the need for co-operation in work which has for its ultimate object the presentation of a picture that is geological rather than physical. In conclusion, he described the successful employment of the Schlumberger method for correlating strata in boreholes. Electrodes are lowered down the boreholes and the resistivity of the adjacent rock is determined at intervals and plotted as a profile characteristic of the strata passed through. Very striking sets of profiles from groups of boreholes were shown, but caution was indicated since the results are affected by the methods of boring used, especially the nature of the mud; and the resistance of the rock itself may have widely differing values according to the presence of interstitial oil or saline waters.

To sum up : the meeting once again indicated the wide use now made of geophysical methods, and their acceptance in fact as one of the most important tools of geological research. The restrictions in their use are at present largely due to their relative novelty and rather high cost, which in Great Britain has tended to restrict their employment to commercial enterprise.

\section{OBITUARIES}

\section{Captain John D. S. Pendlebury}

$\mathrm{C}$ ASSICAL and prehistoric archæology suffer a severe loss in the death, during the invasion of Crete, of Captain John D. S. Pendlebury. He was the son of Herbert S. Pendlebury, a well-known London surgeon, and was educated at Winchester College and Pembroke College, Cambridge, where he held an exhibition and represented the University, and also England, in the high jump in 1926-27. As an undergraduate he showed already the high promise in classical scholarship and in archøology which he fulfilled in later years, and, on graduating in thy first class of the Classical Tripos, he was awarded the School Studentship in the British School of Archæology at Athens (1927-28) followed by the Macmillan Studentship in 1928-29. He took part in excavations on prehistoric sites in Macedonia, and at Armant and Tell-el-Amarna in 1928 and 1929. This combination of Agean and Oriental interests enabled him to put together in Algyptiaca (1930) a 'corpus' of scarabs and other objects of Egyptian workmanship found on prehistoric sites in Greek lands, and he projected, with his scholarly and accomplished wife, a similar record of Figean objects found in Egypt.

In 1930, Pendlebury was appointed curator of Knossos, in succession to Duncan Mackenzie, who had for many years been the principal assistant of Sir Arthur Evans. Here was a post which gave full scope to his abilities, for he was a persistent traveller and field-observer, and had the genial temperament which endeared him to all classes of Cretans. At Knossos itself there was still much to be done: supplementary excavation to elear up obscurities, reinforcement of repairs and precautions against weather damage to the 'Palace' ; the preparation of a much-needed "Handbook to the Palace of Minos" (1933); and the classification, storage and calendaring of a very large accumulation of potsherds and other objects not needed by the Candia Museum, and indeed indispensable for minute study of the ruins. His intimate knowledge of the whole island found record in a larger handbook of the "Archæology of Crete" (1939).

It was part of the original arrangement that Pendlebury should continue during the winter months his direction of the Egypt Exploration Society's work at Tell-el-Amarna, but by 1934 the Egyptian and the Cretan duties had begun to conflict, and to the general regret Pendlebury resigned the curatorship of Knossos. For unforeseen reasons, however, the Egyptian work came to an end, and he found it possible to devote himself in his private capacity wholly to Cretan archæology. His memoir "City of Akhenaten II", published in 1933, gives a full account of his work in Egypt.

Thenceforward, with his wife, and a succession of younger students of the British School of Archæology, Pendlebury carried on minute and intensive exploration in the Lasithi highland, below the Dictæan Cave at Psychro, already excavated by the School ; and the results of this have now appeared in a separate volume of the School's Annual $(38,1937-38)$ as well as current reports in earlier volumes; a remarkable record of the human occupation of this secluded region from the early Bronze Age until it became a refuge and last fortress of the Minoan people after the Iron Age invaders had conquered the lowlands of Crete. 